\title{
Chemically Diverse Multifunctional Peptide Platforms with Antimicrobial and Cell Adhesive Properties
}

\author{
Helena Martin-Gómez ${ }^{[a, b]}$, Lluís Oliver-Cervelló[a,b], Judit Buxadera-Palomero[a,b], Maria-Pau \\ Ginebra $^{[a, b]}$, Carlos Mas-Moruno*[a,b]
}
[a] Department of Materials Science and Engineering, Biomaterials, Biomechanics and Tissue Engineering Group (BBT), Universitat Politècnica de Catalunya (UPC), 08019 Barcelona (Spain)
[b] Barcelona Research Center in Multiscale Science and Engineering, UPC, 08019 Barcelona (Spain)

\begin{abstract}
Bacterial infections and incomplete biomaterial integration represent major problems that can lead to failure of medical implants. However, simultaneously addressing these two issues remains a challenge. Here, we present a chemical peptide library based on a multifunctional platform containing the antimicrobial peptide LF1-11 and the cell adhesive motif RGD. The scaffolds were customized with catechol groups to ensure the straightforward functionalization of the implant surface, and linkers of different length to assess the effect of peptide accessibility on the biological response. The peptidic platforms significantly improved the adhesion of mesenchymal stem cells and showed antimicrobial effects against Staphylococcus aureus. Of note, the peptides bearing too long spacers displayed the lowest efficiency. Subsequently, we designed a platform replacing linear by cyclic RGD, which further enhanced eukaryotic cell adhesion while retaining excellent antimicrobial properties, thus being a suitable candidate for tissue engineering applications.
\end{abstract}

Titanium implants are nowadays widely used to replace non-functional teeth or bone in dentistry and orthopedics, respectively. However, bacterial infection and incomplete material integration with surrounding tissues (i.e. osteointegration) are still critical problems that compromise the long-term success of the implant. ${ }^{[1,2]}$ To address this, extensive effort has been devoted to either inhibiting bacterial colonization ${ }^{[3-5]}$ or ameliorating implant biointegration. ${ }^{[6-8]}$ Nevertheless, simultaneously addressing these two issues remains a challenge..$^{[1,9,10]}$ For instance, anti-fouling polymers like polyethylene glycol (PEG) have been studied as biomaterial coatings due to their capacity to repel bacterial attachment, ${ }^{[11-13]}$ but they concomitantly reduce the adhesion of eukaryotic cells and require the incorporation of cell binding cues. ${ }^{[14-16]}$ The use of classical antibacterial agents such as silver and antibiotics, while effective in killing bacteria, is associated with antimicrobial resistance, toxicity and may also detrimentally affect osteoblastic responses. ${ }^{[1,9]}$ The development of antibacterial nanostructures can overcome the limitations of bactericidalreleasing coatings, but the topographies with the ability to kill bacteria (e.g. with high aspect-ratio features) often compromise the adhesion and differentiation of host cells. ${ }^{[17]}$

In response to these shortcomings, synthetic peptides stand out as powerful and alternative tools to biofunctionalize medical implants. As a matter of fact, antimicrobial peptides (AMPs) have emerged as a viable option to confer antibacterial properties to biomaterials. ${ }^{[18,19]}$ In general, AMPs are cationic and adopt an amphipathic structure that kills bacteria by disrupting their cell membrane, without affecting eukaryotic cells. ${ }^{[20-22]}$ One representative example is the AMP LF1-11, derived from the 1-11 region of lactoferrin, which in previous reports showed the capacity to efficiently inhibit bacterial attachment and biofilm formation on titanium surfaces. ${ }^{[23,24]}$ Additionally, AMPs can be combined with integrin-binding peptides to install cell adhesive properties, thus reaching a dual biological potential. ${ }^{[15,25]}$

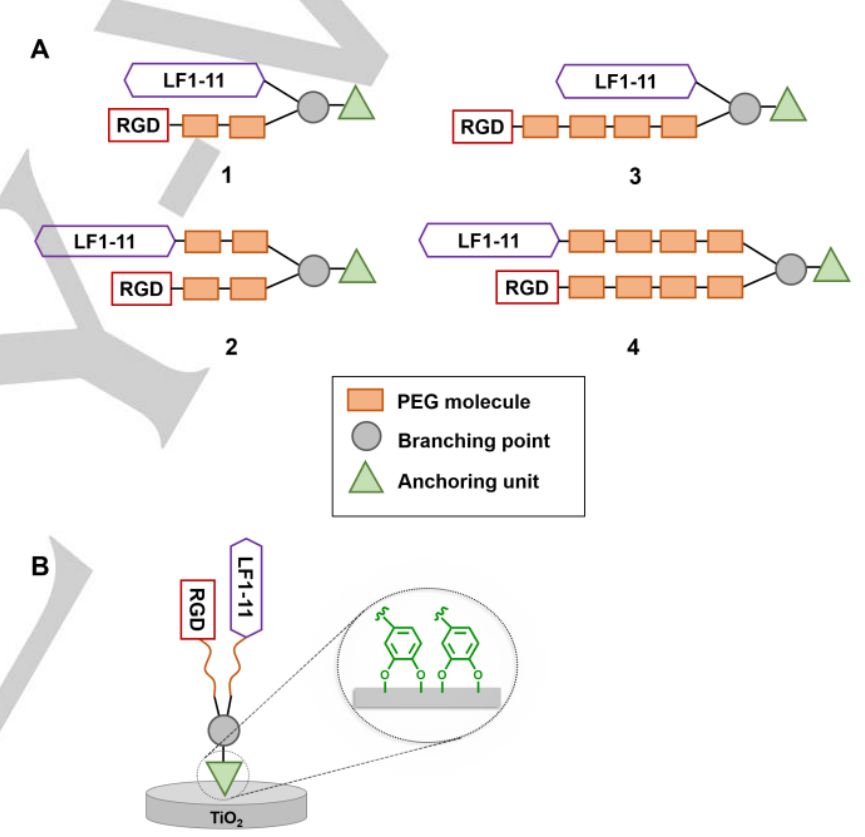

Figure 1. Schematic representation of $A$ ) the structure of the multifunctional peptides, and B) the binding of the molecules to titanium implants via catechol anchoring groups.

Following this rationale, the aim of the present work was to design a small set of multifunctional peptides with antimicrobial and cell adhesive properties (Figure 1). Such design was based on a peptide-based platform previously reported by us that allows the combination of multiple peptide motifs in a modular and chemically controlled fashion. ${ }^{25,26]}$ In detail, the molecules designed contain the potent AMP LF1-11 ${ }^{[23,24]}$ and the well-known cell adhesive sequence RGD. ${ }^{[27-29]}$ Furthermore, the peptides incorporated two catechol groups as anchoring units and PEGbased spacers. More specifically, taking as a reference platform 1, which showed promising biological activity in a previous study, ${ }^{[25]}$ three other analogues were included (2-4) containing different number of short PEG chains in either one or both branches (Figure 1A). Thus, our design included two key features. On the one hand, catechol moieties, which bind with very strong affinity titanium oxides by simple chemisorption ${ }^{[30,31]}$ (Figure 1B); 
on the other hand, the use of different spacer lengths, which facilitates studying the correlation between peptide accessibility and the biological response. ${ }^{[32-34]}$
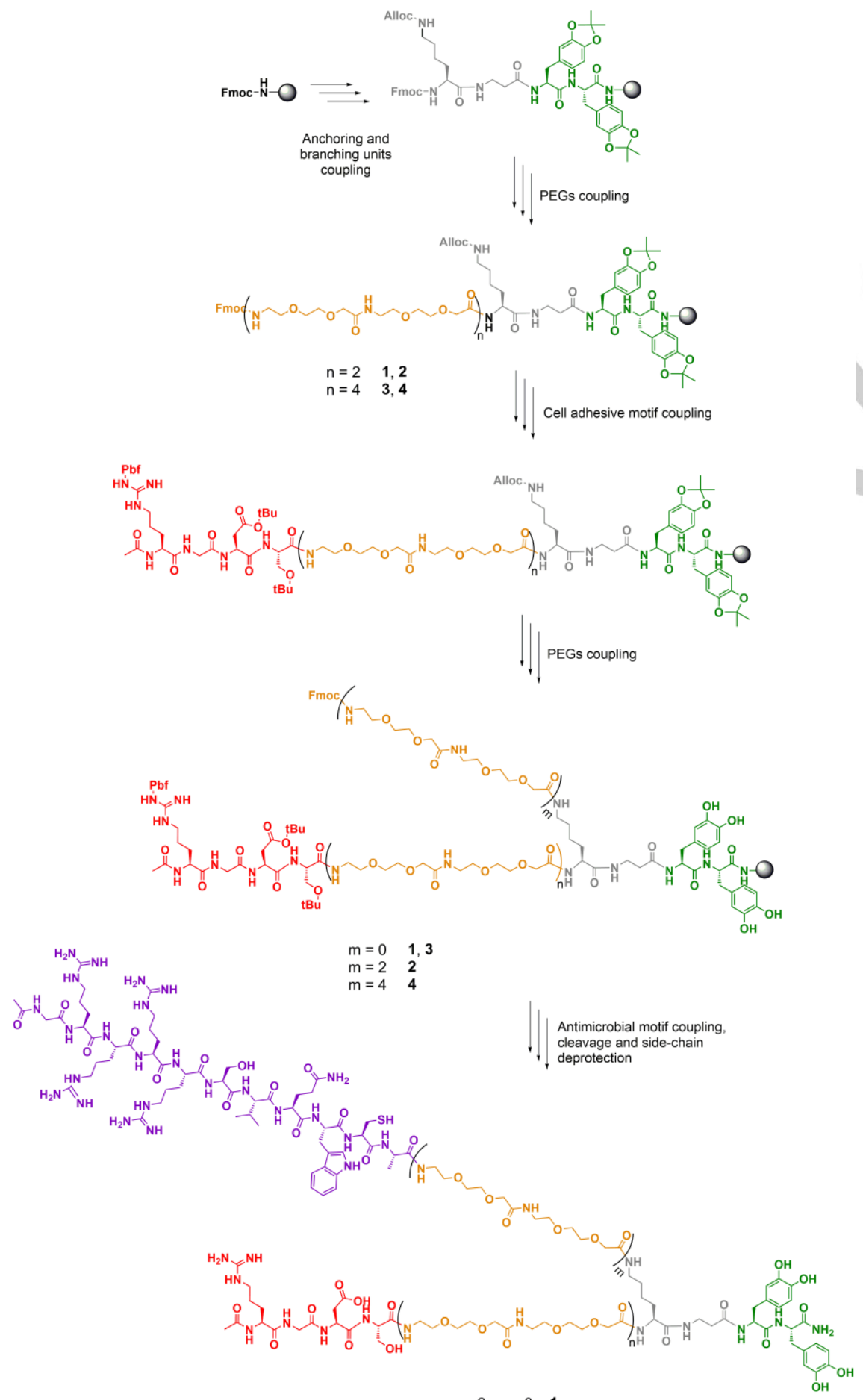

$\mathrm{n}=2, \mathrm{~m}=0$

$\mathrm{n}=2, \mathrm{~m}=2 \quad 2$

$n=4, m=0 \quad 3$

Scheme 1. General strategy for the synthesis of peptides $1-4$.

The peptides were synthesized stepwise manually using solid-phase peptide synthesis (Scheme 1). A crucial element of our strategy was the introduction of two catechol groups at the $C$-terminus as protected Fmoc-L-DOPA(acetonide)-OH residues, which will serve as anchoring points to the titanium surfaces. The second relevant feature was the presence of a branching unit in the form of Fmoc-L-Lys(Alloc)-OH, allowing for selective removal of amino protecting groups and the sequential construction of the two branches. Thus, the cell adhesive motif was synthesized by first introducing two (1, 2) or four $(3,4)$ PEG chains, followed by the coupling of the linear RGDS sequence. Afterwards, the antibacterial branch containing the LF1-11 peptide was elongated in a similar manner, but incorporating none $(\mathbf{1}, \mathbf{3})$, two (2) or four (4) PEG spacers. Final deprotection and cleavage was carried out by treatment with TFA in the presence of TIS as scavenger and water. The peptides were purified by semi-preparative RP-HPLC and characterized by analytical RP-HPLC and MALDI-TOF (Full synthetic and characterization details are found in the Supplementary Information).

In order to assess the cell adhesive and antibacterial properties of the multifunctional peptidic platforms, model titanium surfaces were functionalized via catechol-assisted chemisorption. In detail, the immobilization was attained by simply depositing a $100 \mu \mathrm{L}$ drop of the solution containing the peptides, thereby exploiting the high affinity of catechol groups to bind titanium oxide through the formation of stable coordinative bonds. ${ }^{[30,31,35]}$ Moreover, this approach simplifies the functionalization process, compared to other methods like silanization that require the activation and chemical modification of the surfaces. ${ }^{[25,36,37]}$ The successful attachment of the peptides to titanium was analyzed by means of Raman spectroscopy and XPS measurements. As shown in Figure S8 the presence of the peptides was confirmed by an increase in the percentage of the XPS N1s signal, which can be univocally attributed to the amide bonds and side chains of the peptidic scaffolds. The values of $\mathrm{N} 1 \mathrm{~s}$, which range from $\approx 7.6$ to $9.5 \%$, are indicative of a full coverage of the surface. ${ }^{[26,38,39]}$ In agreement with that, mapping of the amide signal by Raman spectroscopy (1230-1380 $\left.\mathrm{cm}^{-1}\right)$, revealed a homogenous distribution of the peptide on the functionalized surface (Figure S9). Moreover, the Ti2p signal was attenuated after the functionalization, further proving the deposition of a peptide layer of $\approx 2-3 \mathrm{~nm}$ on top of the surfaces (Table S1).[36,37] No significant differences were observed between the different coatings, indicating a similar grafting efficiency for all molecules.

Cell adhesion was then tested with human mesenchymal stem cells (MSCs). After $6 \mathrm{~h}$ of incubation, all peptides significantly improved $(p<0.05)$ the number of adhering MSCs compared to 
non-functionalized titanium, in good agreement with the integrinbinding properties of the RGDS sequence. ${ }^{[8,27,40]}$ The lack of activity of the LF1-11 peptide in promoting cell adhesion as well as the specificity of the RGDS peptide were demonstrated in previous studies. ${ }^{[25,26,37]}$ No significant differences were observed between using two (1 and $\mathbf{2}$ ) or four (3 and $\mathbf{4})$ PEG linkers (Figure $2 \mathrm{~A})$, reaching in all cases cell adhesion efficiencies equal or greater than $50 \%$. Interestingly, the coatings also enhanced the spreading of MSCs, showing statistically larger cell areas than on titanium $(p<0.05)$. Moreover, cell spreading was further promoted by the peptides containing a shorter spacer (1 and 2 ) compared to 3 and $\mathbf{4}$, which have much longer spacers (Figure 2B).
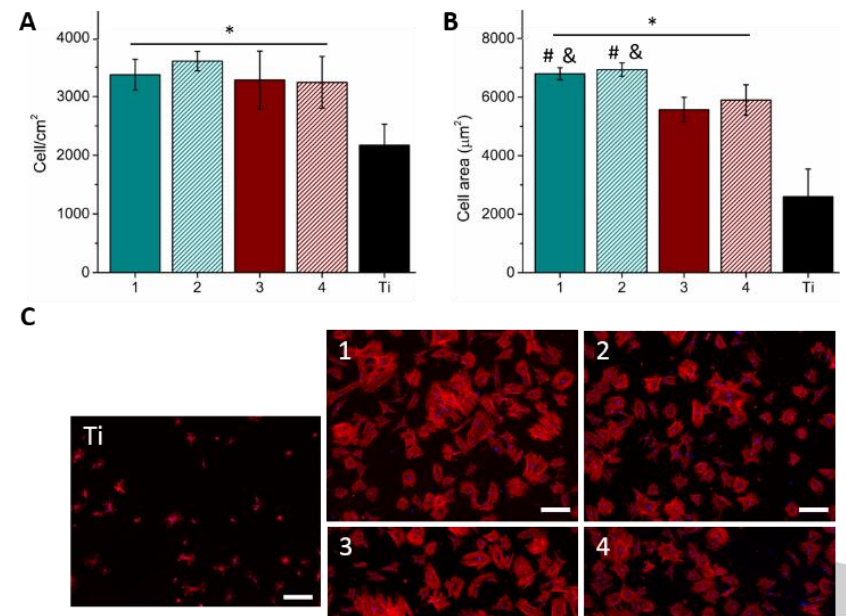

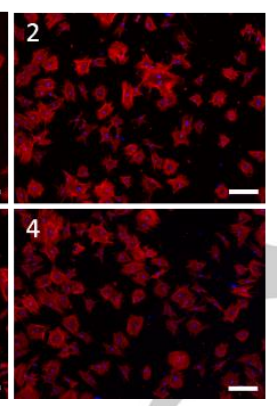

Figure 2. MSCs response to the functionalized titanium surfaces. Cells were seeded at a density of 5000 cells/well and incubated $6 \mathrm{~h}$ in serum-free medium at $37^{\circ} \mathrm{C}$. A) Quantification of cell number. B) projected cell area. C) F-actin immunostaining (scale bar= $200 \mathrm{um}$ ). * indicates statistically significant difference $(p<0.05)$ compared to Ti. \# indicates statistically significant difference $(p<0.05)$ compared to 4 . \& indicates statistically significant difference $(p<0.05)$ compared to 3

This result indicates that, while a minimum spacing distance is required to ensure the accessibility of the RGD motif to interact with integrins, ${ }^{[32,34]}$ above a certain level of length and flexibility of the spacer, the availability of the peptides for cell receptors is compromised. [33] Cell morphology was very similar among all functionalized surfaces, with MSCs exhibiting clear actin filaments and adopting a defined cytoskeleton, which is indicative of an optimal interaction and mechanosensing with the substrates (Figure 2C).

Once the cell adhesive properties of the peptidic platforms were validated, the next step was to investigate whether they exhibited antimicrobial activity as well. To this end, functionalized samples were tested against Staphylococcus aureus, a Grampositive microorganism identified as a common pathogen in the infection of medical implants. ${ }^{[41]}$ As noticed in Figure 3, the presence of LF1-11 significantly reduced the amount of growing bacteria replated on agar, corroborating the antibacterial potential of this peptide. ${ }^{[23,24,25]}$ However, remarkable differences in bacterial inhibition were evident between the molecules. Of note, the highest inhibition of bacterial adhesion was found for $\mathbf{1}$, which contains no spacer in the LF1-11 branch and only a short one in the RGD moiety. Adding a short PEG spacer to LF1-11 (peptide 2 ) or increasing the length of the RGD one (peptide 3) resulted in a slight decrease of the activity. However, combining the longest spacers in both branches in $\mathbf{4}$ was clearly detrimental for the activity. While the importance of having flexible linkers to support the interaction of AMP with bacteria has been documented, ${ }^{[42,43]}$ in our study the incorporation of PEG chains did not bring a positive effect. It is likely that the $C$-terminus of the molecule, which contains the sequence Lys-BAla-DOPA-DOPA (Scheme 1) acts as a pseudo-spacer, providing LF1-11 enough separation from the surface to exert its antibacterial activity. However, in this particular case, further adding a flexible PEG spacer may slightly disturb the presentation of the peptide by e.g. partial coiling or shielding interactions between the PEG chains and the LF1-11 sequence.

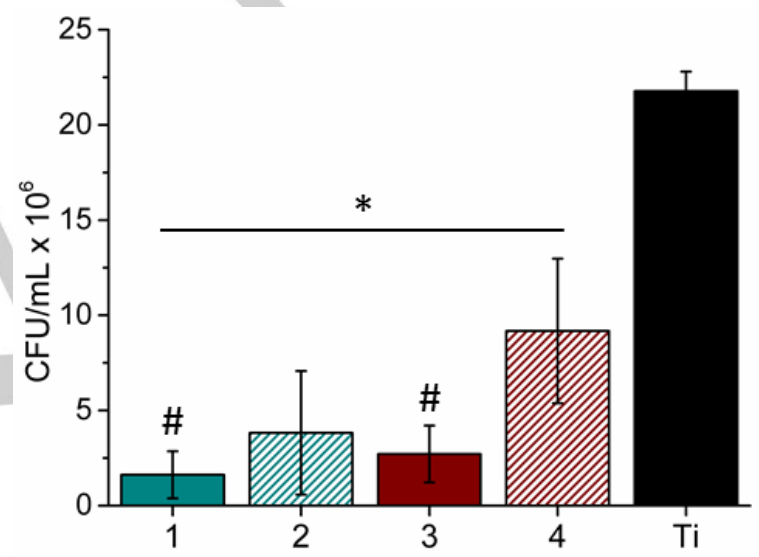

Figure 3. Antibacterial activity of immobilized peptides $\mathbf{1}-\mathbf{4}$ on Ti surfaces. Bacteria were seeded at a concentration of $1 \times 10^{8}$ colony forming units $(\mathrm{CFU}) / \mathrm{mL}$ and incubated for $4 \mathrm{~h}$ at $37^{\circ} \mathrm{C}$. Bacterial counts were measured after detaching adherent bacteria and re-plating them in agar. *indicates statistically significant difference $(p<0.05)$ compared to Ti. \# indicates statistically significant differences $(p<0.05)$ compared to 4 .

Taking into account the biological characterization of the peptidic platforms, compound $\mathbf{1}$ was selected as the best candidate for further optimization, as it showed the highest cell adhesive and antibacterial activity (Figures 2 and 3 ). Thus, in order to improve the cell binding properties of the scaffold, the linear RGD was replaced by its cyclic counterpart, giving rise to platform $\mathbf{5}$ (Figure $4 A)$. It is well established that conformational restriction by cyclization is a powerful strategy to improve the activity and selectivity of peptides. ${ }^{[44]}$ In this regard, the pioneering work of Prof. Kessler showed that the cyclic pentapeptide $c(R G D f X)$ (where $f=D-P h e ; ~ X=$ any amino acid) enhanced the affinity of linear RGD towards $\alpha v \beta 3$ by 1 to 2 orders of magnitude, by stabilizing a $\beta I I / \gamma$ turn, positioning the RGD motif in a tight $y$ turn with Gly in the central position. ${ }^{[40,45,46]}$ Considering the fact that bone forming cells (i.e. MSCs) express $\alpha \mathrm{v} \beta 3$, among other integrins, the cyclic peptide $c(R G D f X)$ has been successfully applied to functionalize biomaterials, showing improved values of cell adhesion in vitro and bone formation in vivo. ${ }^{[8]}$ 
Thus, we synthesized the cyclic peptide $c(R(P b f) G D(O t B u) f E)(6)$, keeping the side chain of glutamic acid unprotected, and coupled the protected peptide to the peptidic scaffold in solid phase using PyBOP as coupling reagent (Scheme S1). ${ }^{[47]}$ The cyclic building block 6 was synthesized on 2-chlortrityl chloride resin (2-CTC), cleaved maintaining the sidechain protecting groups and cyclized in solution. The synthesis of 6 was designed with Gly as the $C$ terminus to minimize side-reactions during the cleavage and the cyclization processes, due to the lack of functional side chain and thus, low reactivity. ${ }^{[48,49]}$ This synthetic protocol yielded the new platform 5 , which mimics the structure of $\mathbf{1}$, but replaces linear RGD by its cyclic version (Scheme S1 and Figure 4A).

Finally, the biological potential of platform $\mathbf{5}$ in terms of MSC adhesion and antibacterial activity against $S$. aureus was investigated and compared to the original platform 1. As expected platform 5 improved MSC adhesion on titanium, showing a significantly higher $(p<0.05)$ number and spreading of cells (Figure 4B, 4C and 4D). Moreover, in comparison with 1, the presence of the cyclic RGD also statistically enhanced $(p<0.05)$ the number of adhering cells and supported the highest levels of cell spreading, thus corroborating the potential of this peptide to coat implant surfaces. ${ }^{[8,34,50]}$ Last but not least, platform $\mathbf{5}$ was capable of inhibiting $S$. aureus adhesion to the surfaces, showing values of inhibition statistically comparable to those of platform 1 (Figure 4E); and therefore, proving that the cyclic RGD conformation and the subsequent increase in integrin binding affinity do not influence the antibacterial activity.
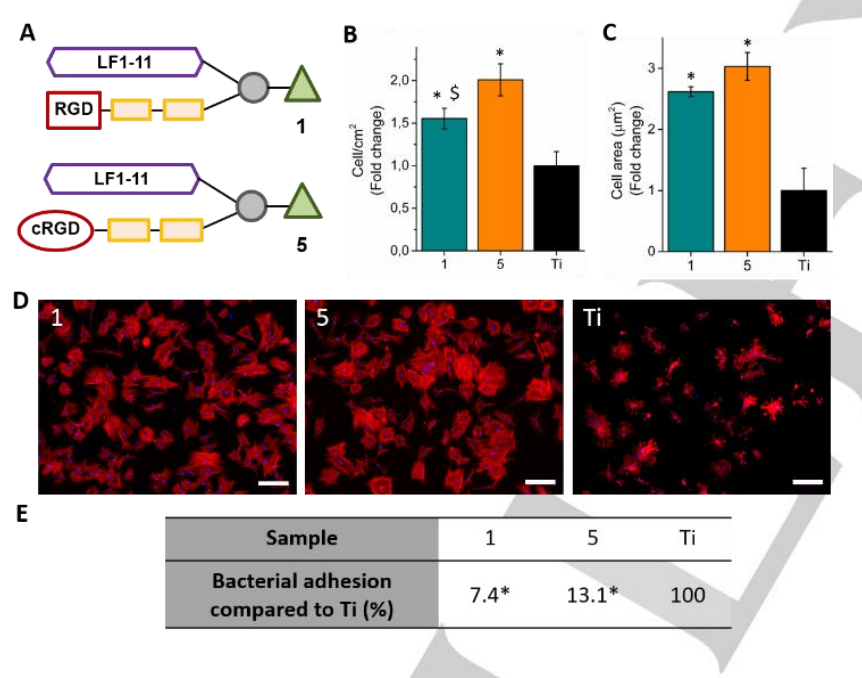

Figure 4. Biological characterization of functionalized surfaces with peptide platforms 1 and $\mathbf{5}$, compared to Ti control. MSCs were seeded at a density of 5000 cells/well and incubated $6 \mathrm{~h}$ in serum-free medium at $37^{\circ} \mathrm{C}$. S. aureus were seeded at a concentration of $1 \times 10^{8} \mathrm{CFU} / \mathrm{mL}$ and incubated for $4 \mathrm{~h}$ at 37 ${ }^{\circ}$ C. A) Schematic representation of the molecules. B) Quantification of MSC number and $\mathrm{C}$ ) projected cell area expressed as a fold change compared to $\mathrm{Ti}$ control. D) F-actin immunostaining of MSCs (scale bar= $200 \mathrm{um}$ ). E) Antibacterial activity of immobilized peptides $\mathbf{1}$ and $\mathbf{5}$ on $\mathrm{Ti}$ surfaces was measured using the agar method and expressed as percentage of bacterial adhesion compared to Ti control. * indicates statistically significant difference $(p<0.05)$ compared to Ti. $\$$ indicates statistically significant difference $(p<0.05)$ compared to 5 .
In conclusion, we developed a straightforward and versatile functionalization technique to confer cell adhesive and antibacterial properties to titanium. A series of bioactive multifunctional platforms were synthesized, consisting of RGD and LF1-11 peptides, catechol anchoring units and PEG linkers. Hence, while the anchoring motif provides a single step immobilization to titanium, the versatility of the synthetic routes allowed for the study of different molecular configurations. Our results showed that the incorporation of a short PEG segment in the cell adhesive motif and none in the antimicrobial motif, combined with a cyclic RGD for cell adhesion, yielded the best biological properties, proving that the activity of the peptides may be optimized by finely tuning their conformation and orientation. However, taking into account the reported importance of having long, flexible spacers for other AMPs ${ }^{[42,43]}$ the observed effects may be contingent on the LF1-11 sequence and the method of immobilization. We foresee the reported methodology holds potential to improve the performance of diverse biomaterials.

\section{Acknowledgements}

We thank the Spanish Government for funding through a Ramon y Cajal grant of C.M.M. (RYC-2015-18566) and projects MAT2017-83905-R and RTI2018-098075-B-C21 (MINECOFEDER), the Generalitat de Catalunya for 2017 SGR1165, FI2018 predoctoral fellowship of LL.O.C. and ICREA Academia Award of M.P.G., and the European Union's Horizon 2020 research and innovation program under the Marie SkłodowskaCurie grant agreement No 872869 .

Keywords: antimicrobial peptide $\cdot$ multifunctionality $•$ DOPA $•$ $\mathrm{RGD} \cdot$ functionalization

J. Raphel, M. Holodniy, S. B. Goodman, S. C. Heilshorn, Biomaterials 2016, 84, 301-314.

[2] S. B. Goodman, Z. Yao, M. Keeney, F. Yang, Biomaterials 2013, 34 3174-3183.

[3] Q. Yu, Z. Wu, H. Chen, Acta Biomater. 2015, 16, 1-13.

[4] S. Ferraris, S. Spriano, Mater. Sci. Eng. C 2016, 61, 965-978.

[5] H. Y. Ahmadabadi, K. Yu, J. N. Kizhakkedathu, Colloids Surfaces B Biointerfaces 2020, 193, 111116.

[6] C. Hu, D. Ashok, D. R. Nisbet, V. Gautam, Biomaterials 2019, 219, 119366.

[7] A. Civantos, E. Martínez-Campos, V. Ramos, C. Elvira, A. Gallardo, A. Abarrategi, ACS Biomater. Sci. Eng. 2017, 3, 1245-1261.

[8] C. Mas-Moruno, R. Fraioli, F. Rechenmacher, S. Neubauer, T. G. Kapp, H. Kessler, Angew. Chemie Int. Ed. 2016, 55, 7048-7067.

[9] C. Mas-Moruno, B. Su, M. J. Dalby, Adv. Healthc. Mater. 2019, 8, 1801103.

[10] S. Spriano, S. Yamaguchi, F. Baino, S. Ferraris, Acta Biomater. 2018, 79, 1-22.

[11] J. Buxadera-Palomero, C. Calvo, S. Torrent-Camarero, F. J. Gil, C. Mas-Moruno, C. Canal, D. Rodríguez, Colloids Surfaces $B$ Biointerfaces 2017, 152, 367-375.

[12] J. Buxadera-Palomero, K. Albó, F. J. Gil, C. Mas-Moruno, D. Rodríguez, Coatings 2020, 10, 456.

[13] A. M. C. Maan, A. H. Hofman, W. M. de Vos, M. Kamperman, Adv. 
Funct. Mater. 2020, 30, DOI 10.1002/adfm.202000936.

[14] K. G. Neoh, X. Hu, D. Zheng, E. T. Kang, Biomaterials 2012, 33, 2813-2822.

[15] M. Hoyos-Nogués, J. Buxadera-Palomero, M.-P. Ginebra, J. M. Manero, F. . Gil, C. Mas-Moruno, Colloids Surfaces B Biointerfaces 2018, 169, 30-40.

[16] L. G. Harris, S. Tosatti, M. Wieland, M. Textor, R. G. Richards, Biomaterials 2004, 25, 4135-4148.

[17] R. Fraioli, P. M. Tsimbouri, L. E. Fisher, A. H. Nobbs, B. Su, S Neubauer, F. Rechenmacher, H. Kessler, M. P. Ginebra, M. J. Dalby, et al., Sci. Rep. 2017, DOI 10.1038/s41598-017-16385-3.

[18] N. G. Fischer, E. A. Münchow, C. Tamerler, M. C. Bottino, C. Aparicio, J. Mater. Chem. B 2020, DOI 10.1039/d0tb01456g.

[19] M. D. T. Torres, S. Sothiselvam, T. K. Lu, C. de la Fuente-Nunez, J. Mol. Biol. 2019, 431, 3547-3567.

[20] N. Strempel, J. Strehmel, J. Overhage, Curr. Pharm. Des. 2014, 21, 67-84.

[21] J. M. Sierra, E. Fusté, F. Rabanal, T. Vinuesa, M. Viñas, Expert Opin. Biol. Ther. 2017, 17, 663-676.

[22] C. de la Fuente-Núñez, M. H. Cardoso, E. de Souza Cândido, O. L. Franco, R. E. W. Hancock, Biochim. Biophys. Acta - Biomembr. 2016, 1858, 1061-1069.

M. Godoy-Gallardo, C. Mas-Moruno, K. Yu, J. M. Manero, F. J. Gil, J. N. Kizhakkedathu, D. Rodriguez, Biomacromolecules 2015, 16, 483-496.

M. Godoy-Gallardo, C. Mas-Moruno, M. C. Fernández-Calderón, C. Pérez-Giraldo, J. M. Manero, F. Albericio, F. J. Gil, D. Rodríguez, Acta Biomater. 2014, 10, 3522-3534.

[25] M. Hoyos-Nogués, F. Velasco, M.-P. Ginebra, J. M. Manero, F. J. Gil, C. Mas-Moruno, ACS Appl. Mater. Interfaces 2017, 9, 2161821630.

[26] C. Mas-Moruno, R. Fraioli, F. Albericio, J. M. Manero, F. J. Gil, ACS Appl. Mater. Interfaces 2014, 6, 6525-6536.

[27] U. Hersel, C. Dahmen, H. Kessler, Biomaterials 2003, 24, 43854415.

[28] M. D. Pierschbacher, E. Ruoslahti, Nature 1984, 309, 30-33.

[29] E. Ruoslahti, M. D. Pierschbacher, Cell 1986, 44, 517-518.

[30] H. Lee, S. M. Dellatore, W. M. Miller, P. B. Messersmith, Science (80-. ). 2007, 318, 426-430.

[31] M. Pagel, R. Hassert, T. John, K. Braun, M. Wießler, B. Abel, A. G. Beck-Sickinger, Angew. Chemie - Int. Ed. 2016, 55, 4826-4830.

[32] F. Rechenmacher, S. Neubauer, C. Mas-Moruno, P. M. Dorfner, J. Polleux, J. Guasch, B. Conings, H.-G. Boyen, A. Bochen, T. R. Sobahi, et al., Chem. - A Eur. J. 2013, 19, 9218-9223.

[33] D. Pallarola, A. Bochen, H. Boehm, F. Rechenmacher, T. R. Sobahi, J. P. Spatz, H. Kessler, Adv. Funct. Mater. 2014, 24, 943-956.

[34] C. Mas-Moruno, P. M. Dorfner, F. Manzenrieder, S. Neubauer, U. Reuning, R. Burgkart, H. Kessler, J. Biomed. Mater. Res. Part A 2013, 101A, 87-97.

[35] P. Kord Forooshani, B. P. Lee, J. Polym. Sci. Part A Polym. Chem. 2017, 55, 9-33.

[36] R. Fraioli, S. Neubauer, F. Rechenmacher, B. M. Bosch, K. Dashnyam, J. H. Kim, R. A. Perez, H. W. Kim, F. J. Gil, M. P. Ginebra, et al., Biomater. Sci. 2019, 7, 1281-1285.
A. Rezania, R. Johnson, A. R. Lefkow, K. E. Healy, Langmuir 1999, 15, 6931-6939.

[39] S. J. Xiao, M. Textor, N. D. Spencer, M. Wieland, B. Keller, H. Sigrist, J. Mater. Sci. Mater. Med. 1997, 8, 867-872.

[40] T. G. Kapp, F. Rechenmacher, S. Neubauer, O. V. Maltsev, E. A. Cavalcanti-Adam, R. Zarka, U. Reuning, J. Notni, H.-J. Wester, C. Mas-Moruno, et al., Sci. Rep. 2017, 7, 39805.

[41] M. M. Fürst, G. E. Salvi, N. P. Lang, G. R. Persson, Clin. Oral Implants Res. 2007, 18, 501-508.

[42] A. Hasan, K. Lee, K. Tewari, L. M. Pandey, P. B. Messersmith, K. Faulds, M. Maclean, K. H. A. Lau, Chem. - A Eur. J. 2020, 26, 5789-5793.

[43] G. Gao, K. Yu, J. Kindrachuk, D. E. Brooks, R. E. W. Hancock, J. N. Kizhakkedathu, Biomacromolecules 2011, 12, 3715-3727.

[44] H. Kessler, Angew. Chemie Int. Ed. English 1982, 21, 512-523.

[45] R. Haubner, R. Gratias, B. Diefenbach, S. L. Goodman, A. Jonczyk, H. Kessler, J. Am. Chem. Soc. 1996, 118, 7461-7472.

[46] M. Aumailley, M. Gurrath, G. Müller, J. Calvete, R. Timpl, H. Kessler, FEBS Lett. 1991, 291, 50-54.

[47] F. Albericio, J. M. Bofill, A. El-Faham, S. A. Kates, J. Org. Chem. 1998, 63, 9678-9683.

[48] C. Mas-Moruno, J. G. Beck, L. Doedens, A. O. Frank, L. Marinelli, S. Cosconati, E. Novellino, H. Kessler, Angew. Chemie Int. Ed. 2011, 50, 9496-9500.

[49] J. Bodanszky, Miklos; Martinez, Synthesis (Stuttg). 1981, 333-356. Diefenbach, B. Nies, G. Hölzemann, S. L. Goodman, H. Kessler, ChemBioChem 2000, 1, 107-114. 


\section{Entry for the Table of Contents}

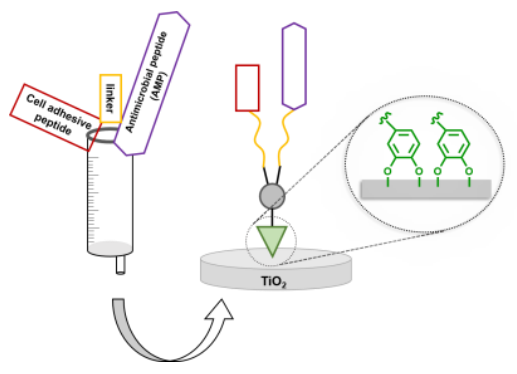

A multifunctional platform containing a cyclic RGD motif and an antimicrobial peptide, presented using finely tuned spacing units, was found to achieve optimal cell adhesive and bacterial inhibition properties. Anchorage to the biomaterial surface through catechol groups enabled a straightforward functionalization of the implant surface. 